\title{
REVIEWS OF BOOKS
}

Handbook of Diagnosis and Treatment of Venereal Diseases. By A. E. W. McLachlan, M.B., Ch.B., D.P.H., F.R.S.Ed. 371 pp. E. \& S. Livingstone, Edinburgh, 2nd edition, 1945. Price 15s.

The speedy appearance of a second edition of this work has confirmed the opinion expressed in the review of the first edition in the Journal last year, that it would prove to be very quitable as a small practical handbook for students and practitioners. The general arrangement of chapters and subject material remains unchanged, and the high standard of the format and of the reproduction of photographs is maintained.

Brief but adequate details of the use of penicillin in the treatment of gonorrhoea and syphilis, which were absent in the first edition, are now included.

\section{CORRESPONDENCE}

Letters are welcome on all matters of general interest. Publication does not necessarily imply that the Editor agrees with the views expressed.

\section{PENICILLIN THERAPY OF EARLY SYPHILIS}

Sir,-It is with great interest that I have read the discussions of my paper, "Penicillin Therapy of Early Syphilis", which was so kindly read by Colonel Harrison in my absence from the last Annual Meeting of the Medical Society for the Study of Venereal Diseases and published in the December 1945 number of the Journal (p. 139). At this late date, a year after the material for the paper was collected, and with the admitted advantage of considerable "hindsight", I venture to submit a few remarks in reply. It is, however, more difficult to write with assurance about the penicillin therapy of syphilis at the present time than it was a year ago, because the subject is in a state of some confusion in the United States of America at the present time.

The plain fact of the matter is that penicillin of the same antisyphilitic potency as that available to us at the time when our patients in the American Army were treated in 1944, is not regularly obtainable at the present time. The evidence for this statement is given below, but first I should like to reply to some of the speakers in the discussion of the paper in question.

It was felt by some of the speakers that my paper painted too hopeful a picture regarding the effect of penicillin upon patients with early syphilis. This was a matter of some surprise to me because, on returning to the United States, $I$ had been chided in certain quarters for having been less sanguine about this method of treatment than I should have been. In retrospect, I am convinced that the physicians in the American Army in the European Theatre of Operations would have been unable to have managed early syphilis by any prolonged or intensive method of treatment as effectively as they did with penicillin. Its use still remains the safest and least toxic method of treatment, controls infectiousness promptly, and has an enormous advantage over any other method of treatment on the score of completion of the prescribed therapy in the specified length of time. In connexion with this, after having been concerned for a considerable period of time with prevention of interruption of prolonged arseno-bismuth therapy in army personnel, I am both relieved and disturbed to say that the interruptions to treatment that occurred in the Army were less than those which are seen in a very large proportion of civil patients, at least in the United States of America.

Sensitivity reactions to penicillin therapy seem to be somewhat on the increase, although they still do not exceed 2-3 per cent, and are usually minor, or are controllable with the antihistamine preparation, Benadryl. As compared with the reactions to arseno-bismuth systems of treatment-especially intensive methods-they still are responsible for only a minor incidence of interruptions to treatment for syphilis.

The remarks of Dr. F. R. Selbie were interesting and significant. He has demonstrated that a satisfactory incidence of cure of syphilis may be obtained in the rabbit by the simultaneous administration of doses of penicillin and of an arsenical compound which, given alone, are subcurative. These results are in accord with the findings of Eagle, Magnuson, and Fleishman (as given in the Journal of Venereal Disease Information for January 1946, p. 3), whose experiments apparently were carried out at about the same time as Dr. Selbie's. It seems to be clearly established, therefore, that in the treatment of experimental syphilis in the rabbit, penicillin and trivalent arsenical compounds have an additive, or possibly even a synergistic effect, and this seems to be true also in man. In so far as I am aware, there are no conclusive data upon the effects of penicillin plus bismuth, although this combination is being widely used in the United States of America at the present time. Dr. Selbie's prediction, that possibly 10,000,000 units of penicillin would be required to cure early syphilis, may not be far wide of the mark. The revised experimental treatment schedules in use in the United States all tend toward a much higher dose of penicillin, if this compound is to be used alone.

The crucial importance of early diagnosis in the curability of syphilis with penicillin, which was clearly indicated by our own data, on the basis of percentages of patients achieving seronegativity, has been abundantly corroborated in many quarters. There seems to be little question that the 


\section{CORRESPONDENCE}

cure rate following penicillin treatment of early syphilis is dependent upon the speed with which the diagnosis is established, and treatment begun, after infection. The experience in the treatment of early syphilis in military personnel indicates an over-all "cure" rate from penicillin alone which cannot be obtained in civil patients. Among patients in Philadelphia, at least, it is uncommon to see early syphilis in the seronegative primary stage, whereas in army patients, between 40 and 50 per cent of all early syphilis was diagnosed in this stage. Almost half the number of patients in the Army, therefore, had a 10-25 per cent better chance of cure of their infection than do 90 per cent. of patients encountered in civil practice. The effect of this circumstance upon the over-all "cure" rate in army personnel is clear.

It has recently become apparent, in the experience of various clinics cooperating in the nation-wide study of the penicillin therapy in early syphilis in the United States, that the results in patients treated since 1944 are less satisfactory, both in terms of cumulative relapse rates and percentage of patients achieving seronegativity, than had been obtained in patients treated prior to that date. This has prompted the release of a joint statement, "The Changing Character of Commercial Penicillin with Suggestions as to the use of Penicillin in Syphilis',, by the United States Public Health Service, the Food and Drug Administration and the Committee on Medical Research. This statement will have appeared in the Journal of the American Medical Association by the time of your receipt of this letter, but a brief summary of it may be of interest to your readers. . The chief facts are as follows.

(1) There has been a gradual increase in the percentage of unsatisfactory results following treatment of early syphilis with penicillin since May 1944.

(2) Some commercial penicillins have shown a greatly decreased effectiveness in the cure of rabbit syphilis as compared with penicillin available 2 years ago.

(3) On the basis of studies carried out by Eagle, Fleming, Mahoney, and Arnold, and by Chesney, it "was apparent that there was at least a tenfold difference between the in vivo activity of penicillin $G$ and penicillin $K$, and that the latter drug was at least relatively ineffective in rabbit syphilis'".

(4) Probably as a gradual phenomenon during 1944, a change in the relative percentage in various penicillin fractions contained in commercial penicillin has occurred ; $" .$. the G content in the product of some, if not all, manufacturers decreased markedly, with a relative increase in fractions $F$ and $K$, especially the latter' '.

The first portion of the statement contains the following concluding paragraph: "The conclusion seems inescapable that certain commercial penicillins within recent months are less efficacious in treatment of syphilis than were the preparations available two years ago. It is probable that some of the decreased therapeutic effect is due to the increased amount of penicillin $K$ which has been present in the commercial preparations of many manufacturers. The existence of other factors, such as the decrease in the amount of possibly therapeutically active impurities, must also be reckoned with. These several factors are under further intensive study in a number of cooperating institutions. The penicillin manufacturers are likewise aware of the situation, are cooperating in the study, and are taking practical steps in production to correct the identifiable difficulties.',

These factors, quite understandably, have stimulated renewed activity among the various agencies interested in the experimental and clinical investigations concerning penicillin in the treatment of syphilis in the United States. It is apparent that these investigations must be continued for a long period of time before definite answers to many questions will be established. The question as to how best to treat early syphilis now is the subject of much discussion among syphilologists. On one matter, however, I think that there is a general agreement : namely that penicillin is by far the best and safest drug available for the treatment of syphilis. It is still successful in a very great proportion of patients with early syphilis. There are some authorities who would prefer to use it alone, in a larger total dose, and with injections given more frequently ; others would combine it with Mapharside or bismuth or both.

At the present time, in patients treated for seropositive early syphilis under my direction, the following schedule is employed.

$\begin{array}{ll}\text { Penicillin } & \left\{\begin{array}{l}3,600,000 \text { units in } 60 \text { doses of } 60,000 \text { units each, given at intervals of } \\ 3 \text { hours, plus }\end{array}\right. \\ \begin{array}{l}\text { Mapharside } \\ \text { or analogue }\end{array} & \left\{\begin{array}{l}360 \text { milligrams in } 6 \text { individual doses of } 60 \text { milligrams each, given daily } \\ \text { to young healthy males, and } 3 \text { times weekly to females, plus }\end{array}\right. \\ \text { th subsalicylate } & \left\{\begin{array}{l}1,200 \text { milligrams in } 6 \text { doses of } 200 \text { milligrams each, } \\ 2 \text { or } 3 \text { times weekly. }\end{array}\right.\end{array}$
Bismuth subsalicylate $\left\{\begin{array}{l}1,200 \text { milligrams in } \\ 2 \text { or } 3 \text { times weekly. }\end{array}\right.$

If such treatment is given by doctors of competence, I venture to predict that severe reactions to treatment will be infrequent. Obviously it is an interim schedule to be changed as soon as evidence for a better one becomes available. There are those who would disagree with any schedule which includes Mapharside (or its analogue) on a daily dosage scheme, even for a short period. In patients treated by the 20 -day method in the American Army in Europe, the incidence of serious reactions prior to the seventh or eighth day of treatment, in healthy male patients who had not received an arsenical drug previously, was very small. The results of such treatment, moreover, were highly satisfactory. In present circumstances, it is my feeling that the inherent risk is entirely justifiable in the treatment of syphilis, which is, after all, a disease of some seriousness.

University of Pennsylvania, Philadelphia

I am, etc.

DONALD M. PILLSBURY, M.D. 